\title{
ChemComm
}

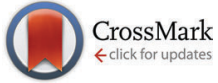

Cite this: Chem. Commun., 2016, 52,950

Received 20th October 2015 Accepted 16th November 2015

DOI: $10.1039 / c 5 c c 08699 j$

www.rsc.org/chemcomm

\section{Phosphonium-containing diblock copolymers from living anionic polymerization of 4-diphenylphosphino styrene $\dagger$}

\author{
Alison R. Schultz, Gregory B. Fahs, Chainika Jangu, Mingtao Chen, Robert B. Moore \\ and Timothy E. Long*
}

Living anionic polymerization of 4-diphenylphosphino styrene (DPPS) achieved well-defined homopolymers, poly(DPPS- $b-S)$ styrenic block copolymers, and poly(l-b-DPPS) diene-based diblock copolymers with predictable molecular weights and narrow polydispersities. In situ FTIR spectroscopy monitored the anionic polymerization of DPPS and tracked monomer consumption for kinetic analysis. Post-alkylation enabled controlled placement of phosphonium functionality in poly(I-b-DPPS) diblock copolymers, producing well-defined phosphonium-containing block copolymers with low degrees of compositional heterogeneity. Incorporating phosphonium charge disrupted the lamellar bulk morphology of the neutral diblock precursor and provided morphologies with interdigitated packing of alkyl chains on the phosphonium cation.

Styrenic block copolymers receive continued attention for the production of thermally stable compositions with tunable physical and mechanical properties, impacting technologies ranging from high performance adhesives ${ }^{1,2}$ and durable coating $\mathrm{s}^{3,4}$ to biomaterials ${ }^{5,6}$ and medical devices. ${ }^{7-10}$ Immiscible block sequences promote microphase separation, facilitating selfassembly into various nanostructured compositions with tailored sequence lengths and volume fractions, molecular weight distribution, and chemical compositions. Tuning structural composition and nanostructured morphologies engineers a vast array of styrenic block copolymers and enables predictable viscoelastic properties for targeted applications. Incorporating ion-containing extended sequences imparts electrostatic interactions for enhancing microphase separation and thermomechanical properties, and provides electromechanical properties suitable for additional technologies involving electro-active ${ }^{11,12}$ and ion exchange membranes. ${ }^{13-15}$

Sulfonated styrenic block copolymers represent exemplary ion-containing compositions, possessing fortified viscoelastic

Macromolecules and Interfaces Institute, Department of Chemistry,

80 Virginia Tech, Blacksburg, VA 24061, USA. E-mail: telong@vt.edu

$\dagger$ Electronic supplementary information (ESI) available: Experimental details and in situ FTIR spectroscopy. See DOI: 10.1039/c5cc08699j behavior and enhanced microphase separation due to synergistic properties of ionomers ${ }^{16,17}$ and block copolymers. ${ }^{18}$ Ionic association within these block compositions increases the Flory-Huggins interaction parameter $\chi$ for microphase separation, allowing for lower block molecular weights and improved microphase separation. ${ }^{19}$ Previous investigations involving sulfonated block copolymers $^{20,21}$ elucidated effects of sulfonation level, molecular weight, and relative humidity on morphologies and electro-active properties, and earlier work predominately focused on Kraton ${ }^{\mathbb{R}}$ sulfonated poly(styrene- $b$-hydrogenated butadiene- $b$-styrene) [poly(SS-b-HB- $b$-SS)] and sulfonated poly(styrene- $b$-hydrogenated isoprene-b-styrene) [poly(SS-b-HI- $b$-SS)] triblock copolymers, ${ }^{22,23}$ and Kraton ${ }^{\circledR}$ sulfonated poly(tert-butyl styrene- $b$-hydrogenated isoprene- $b$-sulfonated styrene- $b$-hydrogenated isoprene- $b$-tert-butyl styrene) [poly( $t \mathrm{BS}-b$-HI- $b$-SS- $b$-HI- $b$ - $t \mathrm{BS})]$ pentablock copolymers (0-50 mol\% sulfonated polystyrene) ${ }^{24-27}$ Although these reports revealed sulfonated block copolymers as promising membranes for technologies ranging from fuel cells and water purification ${ }^{28}$ to actuators ${ }^{29}$ and nanofabrication, ${ }^{30}$ concern for thermal and charge stability due to low temperature degradation reactions poses an architectural design flaw and inspires new directions in polymerizing alternative charged monomers. ${ }^{27,31}$

Recent studies reveal phosphorus-containing macromolecules as promising analogues to sulfonated polymers, revealing tunable oxidation states (phosphates, phosphines, phosphine oxides, and phosphoniums), high alkylation efficiency, ${ }^{32,33}$ thermal and base stability, ${ }^{32,33}$ high ionic conductivity, ${ }^{11,34}$ tailored structures and morphologies, ${ }^{35}$ and ionic aggregation. ${ }^{36}$ Phosphorus-containing monomers exhibiting vinylbenzyl-, acrylate-, and methacrylatepolymerizable units achieves a wide range of phosphoruscontaining macromolecules including homopolymers, ${ }^{37}$ random copolymers ${ }^{38}$ and block copolymers. ${ }^{39,40}$ Although many of these synthetic methods involve controlled free radical strategies, anionic polymerization remains a commercially viable process for producing block copolymers with architectural precision and low degrees of compositional heterogeneity. Herein, we report the controlled anionic polymerization of 4-diphenylphosphino styrene 
(DPPS) as an unprecedented method for achieving novel phosphorus-containing styrenic block copolymers. DPPS does not contain $\beta$-hydrogens to the phosphorus atom that are susceptible for low temperature Hoffman elimination degradation pathways and, consequently, is structurally advantageous for achieving phosphonium-containing block copolymers with enhanced thermal and base stability in comparison to sulfonated styrenic block copolymers. Sequential monomer addition strategies enabled poly(I- $b$-DPPS) block copolymers for elucidating postalkylation effects on structure-morphology behavior. As ioncontaining polymers emerge for electro-active membranes, designing novel phosphonium-containing block copolymers with predictable structure-morphology-property relationships will facilitate commercial technologies.

Scheme 1 depicts anionic polymerization as a facile and controlled approach for achieving poly(DPPS) homopolymers in THF using sec-butyllithium as the initiator. The reaction proceeded at $-78{ }^{\circ} \mathrm{C}$ to maintain stereochemical control of the propagating, deep red poly(styryl)lithium chains under the polar, aprotic solvent conditions. In situ FTIR spectroscopy monitored DPPS propagation, using the $\mathrm{C}=\mathrm{C}$ vinyl vibrational frequency peak at $918 \mathrm{~cm}^{-1}$ and generating a normalized waterfall plot for peak absorbance $v$ s. time (min). Tracking vinyl concentration disappearance over time indicated that complete monomer consumption occurred within $5 \mathrm{~min}$ (S1). Size exclusion chromatography (SEC) confirmed a $30000 \mathrm{~g} \mathrm{~mol}^{-1}$ target $M_{\mathrm{n}}$ value for the homopolymer, and revealed monomodality in the chromatogram and a narrow polydispersity of 1.05 (Fig. 1).

Sequential monomer addition studies with styrene further verified the controlled polymerization of DPPS, revealing

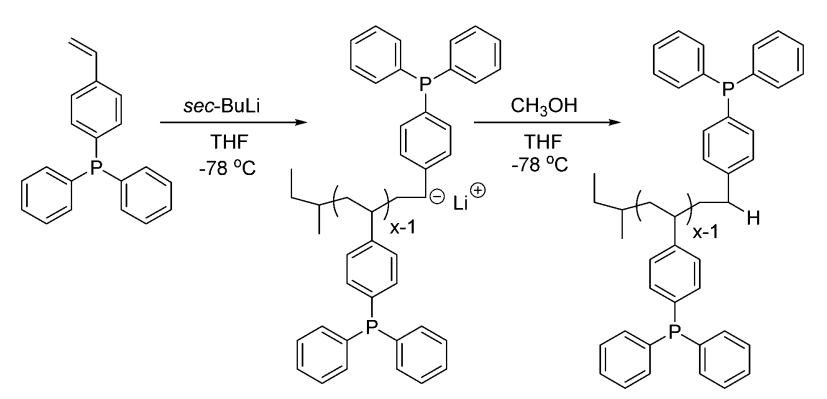

Scheme 1 Anionic polymerization achieves poly(DPPS).

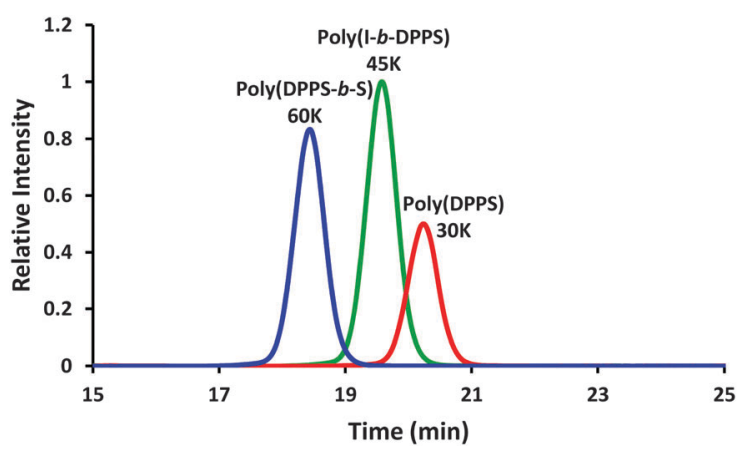

Fig. 1 SEC characterization for poly(DPPS), poly(DPPS- $b$-S) after sequential addition of styrene, and poly(I-b-DPPS). characteristics of a truly "living" polymerization (Scheme 2A). In these studies, sec-butyllithium initiated the anionic polymerization of DPPS and produced living propagating chains with target $M_{\mathrm{n}}$ of $30000 \mathrm{~g} \mathrm{~mol}^{-1}$. Sequential monomer addition enabled the anionic copolymerization with styrene, resulting in a poly(DPPS- $b$-S) block copolymer with final $M_{\mathrm{n}}$ of $60000 \mathrm{~g} \mathrm{~mol}^{-1}$ (PDI = 1.06). SEC chromatograms in Fig. 1 show the molecular weight shift during the sequential addition from poly(DPPS) to poly(DPPS- $b$-S) with narrow molecular weight distributions, which is indicative of living polymerization.

Living anionic polymerization with sequential monomer addition also produced a novel poly(I- $b$-DPPS) diblock copolymer in order to demonstrate the versatility in block composition and architecture (Scheme 2B). Moreover, this experiment elucidated DPPS propagation behavior in nonpolar solvent conditions suitable for targeting 1,4-configuration cis-isomer diene microstructure. For this study, sec-butyllithium first initiated a living poly(isoprene) $\left(M_{\mathrm{n}}=30000 \mathrm{~g} \mathrm{~mol}^{-1}\right)$ due to the insoluble properties of poly(DPPS) in nonpolar solvents. After $2 \mathrm{~h}$, isoprene monomer was completely consumed and DPPS was sequentially added to the living chain in order to produce a second block sequence

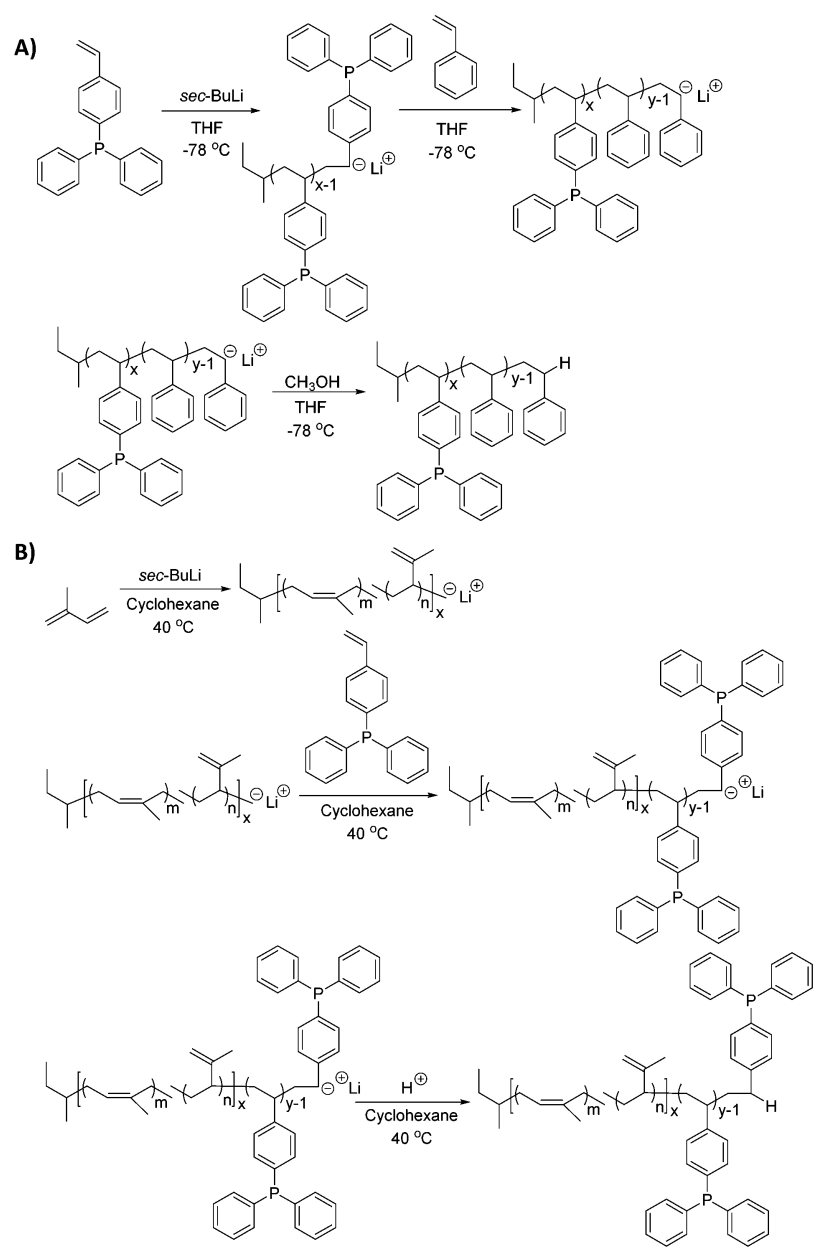

Scheme 2 Sequential monomer addition achieves copolymerization of diblocks (A) poly(DPPS- $b$-S) in polar solvent conditions and (B) poly(I-b-DPPS) in nonpolar solvent conditions. 
$\left(M_{\mathrm{n}}=15000 \mathrm{~g} \mathrm{~mol}^{-1}\right)$ compatible with the polymer solution. The homogeneous, orange reaction mixture stirred for $30 \mathrm{~min}$ to complete DPPS propagation before quenching with acidic methanol. SEC analysis confirmed the total $M_{\mathrm{n}}=45000 \mathrm{~g} \mathrm{~mol}^{-1}$ value for poly(I- $b$-DPPS) and revealed a narrow polydispersity of 1.04 (Fig. 1).

Poly(I- $b$-DPPS) diblock copolymer provided a balance of hard (DPPS, high $T_{\mathrm{g}}=120{ }^{\circ} \mathrm{C}$ ) and soft (I, low $T_{\mathrm{g}}=-50{ }^{\circ} \mathrm{C}$ ) block sequences to fabricate a mechanically robust, free-standing film. Post-alkylation with bromohexane and bromododecane achieved phosphonium based derivatives (Scheme 3), poly(I- $b$ $\left.\mathrm{C}_{6} \mathrm{DPPS}\right)^{+} \mathrm{Br}^{-}$and poly $\left(\mathrm{I}-b-\mathrm{C}_{12} \mathrm{DPPS}\right)^{+} \mathrm{Br}^{-}$, and small angle X-ray scattering analysis (SAXS) was employed to reveal the microphase-separated bulk morphologies of the neutral and charged samples (Fig. 2). All SAXS measurements were performed at room temperature, and all films were slowly cast from toluene and annealed at $120{ }^{\circ} \mathrm{C}$ under reduced pressure $(5 \mathrm{mmHg})$ to facilitate phase separation of the blocks. The neutral poly(I- $b$ DPPS) block copolymer sample exhibited an ordered scattering profile with peak maxima at $q^{*}, 2 q^{*}, 3 q^{*}$, and $4 q^{*}$, indicating a lamellar morphology. Bragg's law was used to approximate lamellar spacing from the primary scattering maximum at $q^{*}$, revealing a Bragg distance of $28 \mathrm{~nm}$. The scattering profile for both poly(I- $\left.b-\mathrm{C}_{6} \mathrm{DPPS}\right)^{+} \mathrm{Br}^{-}$and poly $\left(\mathrm{I}-b-\mathrm{C}_{12} \mathrm{DPPS}\right)^{+} \mathrm{Br}^{-}$exhibit broader scattering maxima compared to the neutral copolymer, presumably due to the incorporated ion associations that prohibit sufficient thermal annealing in these samples. Scattering maxima are observed at $q^{*}, 2 q^{*}, 3 q^{*}, 4 q^{*}$ for poly(I- $\left.b-\mathrm{C}_{6} \mathrm{DPPS}\right)^{+} \mathrm{Br}^{-}$and $q^{*}$, $2 q^{*}$ for poly(I- $\left.b-\mathrm{C}_{12} \mathrm{DPPS}\right)^{+} \mathrm{Br}^{-}$, suggesting a less ordered lamellar

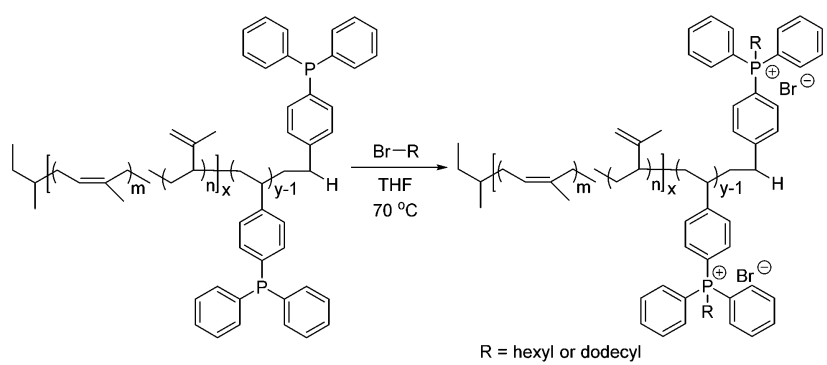

Scheme 3 Post-alkylation produces phosphonium containing diblock copolymers, poly $\left(1-b-\mathrm{C}_{6} \mathrm{DPPS}\right)^{+} \mathrm{Br}^{-}$and poly $\left(\mathrm{I}-b-\mathrm{C}_{12} \mathrm{DPPS}\right)^{+} \mathrm{Br}^{-}$.

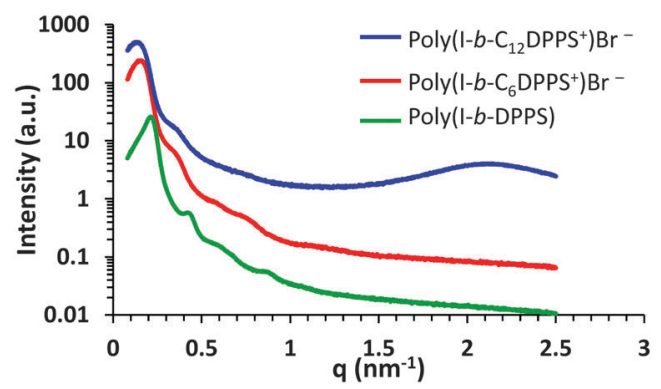

Fig. 2 Small Angle $X$-Ray Scattering profiles reveal bulk morphologies for poly(I-b-DPPS), poly(I-b-C $\left.\mathrm{C}_{6} \mathrm{DPPS}\right)^{+} \mathrm{Br}^{-}$, and poly $\left(\mathrm{I}-b-\mathrm{C}_{12} \mathrm{DPPS}\right)^{+} \mathrm{Br}^{-}$diblock copolymers. Appearance of broad peak in poly $\left(1-b-C_{12} \mathrm{DPPS}\right)^{+} \mathrm{Br}^{-}$scattering profile corresponds to interdigitated bilayers. morphology for both samples compared to the neutral copolymer. The lamellar spacing for both poly(I- $\left.b-\mathrm{C}_{6} \mathrm{DPPS}\right)^{+} \mathrm{Br}^{-}$and poly(I-b$\mathrm{C}_{12}$ DPPS $)^{+} \mathrm{Br}^{-}$is calculated to be $38 \mathrm{~nm}$. Increasing the alkyl length also gave rise to a broad scattering peak at approximately $q=2.1 \mathrm{~nm}^{-1}$, corresponding to the interdigitated packing of dodecyl chains on the phosphonium cation. A similar phenomenon was observed in earlier reports involving random copolymers containing trioctyl phosphonium styrenic ionic liquids. ${ }^{38}$ Tuning film casting conditions and applying transmission electron microscopy (TEM) will further elucidate the morphology of phosphonium-containing diblock copolymers.

Living anionic polymerization afforded novel phosphinecontaining homopolymers and diblock copolymers with targetable molecular weights and narrow polydispersities. Sequential monomer addition strategies enabled poly(DPPS- $b$-S) and poly(I- $b$-DPPS) block copolymers for suitable polar and nonpolar solvent conditions. A balance of soft-hard volume fractions for poly(I- $b$-DPPS) block copolymers promoted self-assembly into lamellar microphase separated morphologies. Post-alkylation efficiently converted the phosphine backbone to a phosphonium cation, achieving poly(I- $\left.b-\mathrm{C}_{6} \mathrm{DPPS}\right)^{+} \mathrm{Br}^{-}$and poly(I- $\left.b-\mathrm{C}_{12} \mathrm{DPPS}\right)^{+} \mathrm{Br}^{-}$, which disrupted the bulk morphology of the traditional neutral composition. Increasing the alkyl chain length gave rise to a new phase, corresponding to interdigitated packing of dodecyl chains on the phosphonium cation. Future studies will extend these novel phosphonium diblock compositions to ABA- and ABC-type triblock architectures, in order to evaluate these phosphonium-containing styrenic block copolymers as ioncontaining thermoplastic elastomers.

We acknowledge the Institute for Critical Technology Applied Science (ICTAS) for laboratory support and we thank Dr Carl Willis of Kraton Polymers for insightful discussions. This material is partially based upon work supported by the National Science Foundation under Grant No. DMR-0923107.

\section{Notes and references}

1 M. F. Tse, J. Adhes. Sci. Technol., 1989, 3, 551.

2 K. A. Mauritz, R. I. Blackwell and F. L. Beyer, Polymer, 2004, 45, 3001.

3 T. Hashimoto, K. Tsutsumi and Y. Funaki, Langmuir, 1997, 13, 6869.

4 M. Ma, R. M. Hill, J. L. Lowery, S. V. Fridrikh and G. C. Rutledge, Langmuir, 2005, 21, 5549.

5 K. Kazunori, Y. Masayuki, O. Teruo and S. Yasuhisa, J. Controlled Release, 1993, 24, 119.

6 G. S. Kwon and K. Kataoka, Adv. Drug Delivery Rev., 1995, 16, 295.

7 S. V. Ranade, R. E. Richard and M. N. Helmus, Acta Biomater., 2005, 1, 137.

8 R. Weiss, J. Fitzgerald and D. Kim, Macromolecules, 1991, 24, 1071.

9 H. B. Park, B. D. Freeman, Z.-B. Zhang, M. Sankir and J. E. McGrath, Angew. Chem., Int. Ed., 2008, 47, 6019.

10 K. Brown, J. C. Hooker and C. Creton, Macromol. Mater. Eng., 2002, 287, 163.

11 A. R. Schultz, P. M. Lambert, N. A. Chartrain, D. M. Ruohoniemi, Z. Zhang, C. Jangu, M. Zhang, C. B. Williams and T. E. Long, ACS Macro Lett., 2014, 3, 1205.

12 R. Gao, M. Zhang, N. Dixit, R. B. Moore and T. E. Long, Polymer, 2012, 53, 1203.

13 R. Gao, D. Wang, J. R. Heflin and T. E. Long, J. Mater. Chem., 2012, 22, 13473.

14 M. H. Allen, M. D. Green, H. K. Getaneh, K. M. Miller and T. E. Long, Biomacromolecules, 2011, 12, 2243.

15 M. H. Allen, Jr., S. Wang, S. T. Hemp, Y. Chen, L. A. Madsen, K. I. Winey and T. E. Long, Macromolecules, 2013, 46, 3037. 
16 K. A. Page, K. M. Cable and R. B. Moore, Macromolecules, 2005, 38, 6472. 17 W. MacKnight, L. DeMejo and O. Vogl, Acta Polym., 1980, 31, 617. 18 R. Weiss, A. Sen, L. Pottick and C. Willis, Polymer, 1991, 32, 2785.

19 J. H. Choi, C. L. Willis and K. I. Winey, J. Membr. Sci., 2012, 169, 394-395.

20 A. Jackson, K. M. Beers, X. C. Chen, A. Hexemer, J. A. Pople, J. B. Kerr and N. P. Balsara, Rev. Sci. Instrum., 2013, 84, 075114.

21 M. J. Park and N. P. Balsara, Macromolecules, 2008, 41, 3678.

22 J.-H. Choi, Y. Ye, Y. A. Elabd and K. I. Winey, Macromolecules, 2013, 46, 5290.

23 Y. A. Elabd, E. Napadensky, C. W. Walker and K. I. Winey, Macromolecules, 2006, 39, 399.

24 J. H. Choi, C. L. Willis and K. Winey, J. Membr. Sci., 2012, 394, 169. 25 Y. A. Elabd, C. W. Walker and F. L. Beyer, J. Membr. Sci., 2004, 231, 181. 26 J. Kim, B. Kim and B. Jung, J. Membr. Sci., 2002, 207, 129.

27 B. Kim, J. Kim and B. Jung, J. Membr. Sci., 2005, 250, 175.

28 X. Wang, M. Goswami, R. Kumar, B. G. Sumpter and J. Mays, Soft Matter, 2012, 8, 3036.

29 M. Shahinpoor, Y. Bar-Cohen, J. Simpson and J. Smith, Smart Mater. Struct., 1998, 7, R15.
30 V. Bocharova, A. L. Agapov, A. Tselev, L. Collins, R. Kumar, S. Berdzinski, V. Strehmel, A. Kisliuk, I. I. Kravchenko and B. G. Sumpter, Adv. Funct. Mater., 2015, 25, 805.

31 R. Gao, M. Zhang, N. Dixit, R. B. Moore and T. E. Long, Polymer, 2012, 53, 1203.

32 H. Ren, J. Sun, B. Wu and Q. Zhou, Polym. Degrad. Stab., 2007, 92, 956.

33 U. A. Rana, R. Vijayaraghavan, M. Walther, J. Sun, A. A. J. Torriero, M. Forsyth and D. R. MacFarlane, Chem. Commun., 2011, 47, 11612.

34 S. T. Hemp, M. Zhang, M. H. Allen, Jr., S. Cheng, R. B. Moore and T. E. Long, Macromol. Chem. Phys., 2013, 214, 2099.

35 Y.-Y. Gu and T. P. Lodge, Macromolecules, 2011, 44, 1732.

36 S. Cheng, M. Zhang, T. Wu, S. T. Hemp, B. D. Mather, R. B. Moore and T. E. Long, J. Polym. Sci., Part A: Polym. Chem., 2012, 50, 166.

37 K. Wang, Y. Zeng, L. He, J. Yao, A. K. Suresh, J. Bellare, T. Sridhar and H. Wang, Desalination, 2012, 292, 119.

38 S. Cheng, M. Zhang, T. Wu, S. T. Hemp, B. D. Mather, R. B. Moore and T. E. Long, J. Polym. Sci., Part A: Polym. Chem., 2012, 50, 166.

39 Y. P. Borguet and N. V. Tsarevsky, Polym. Chem., 2012, 3, 2487.

40 T. Terashima, M. Kamigaito, K.-Y. Baek, T. Ando and M. Sawamoto, J. Am. Chem. Soc., 2003, 125, 5288. 